\title{
ВЛИЯНИЕ МЕТОДОВ РАСПРЕДЕЛЕНИЯ ЗАТРАТ ПРИ ФОРМИРОВАНИИ СЕБЕСТОИМОСТИ ЭНЕРГИИ НА ПРИМЕРЕ ТЭЦ-3 ООО «ТВЕРСКАЯ ГЕНЕРАЦИЯ»
}

\author{
(c) 2019 Сухарева Евгения Викторовна \\ кандидат экономических наук, доцент кафедры Экономики в энергетике и промышленности \\ Национальный исследовательский университет «МЭИ», Россия, Москва \\ E-mail: sukharevayevv@mpei.ru
}

\author{
(c) 2019 Кахальников Максим Владиславович \\ студент кафедры Экономики в энергетике и промышленности \\ Национальный исследовательский университет «МЭИ», Россия, Москва \\ E-mail: maxchus17@gmail.com
}

Авторами раскрыты преимущества комбинированного производства тепловой и электрической энергии на теплоэлектроцентрали (ТЭЦ). Проведен анализ существующих методов распределения затрат при формировании себестоимости энергии на примере ТЭЦ-3 ООО «Тверская генерация».

Ключевые слова: ТЭЦ, комбинированное производство, методы распределения затрат, когенерация, себестоимость энергии.

Электроэнергетика России - это единая энергетическая система, которая представляет собой постепенно развивающийся комплекс, объединенный общим режимом работы и единым централизованным диспетчерским и автоматическим управлением. По своим масштабам ЕЭС России является крупнейшей в мире, а по мощности сопоставима с западноевропейским энергообъединением. Масштабы развития теплоэнергетики в значительной мере определяются такими факторами, как сокращение вводов атомных и гидравлических электростанций, а также ростом объёмов оборудования, вырабатывающего свой парковый ресурс.

Все промышленные предприятия нуждаются одновременно в теплоте и электроэнергии. Некоторым предприятиям теплота требуется только для отопления, вентиляции, кондиционирования воздуха и горячего водоснабжения. Другим предприятиям - металлургическим, химическим, нефтеперерабатывающим, целлюлознобумажным и др. помимо горячей воды (на вышеуказанные цели) требуется пар различных параметров на производственные нужды: обогрев технологических аппаратов, приводы различных механизмов - крупных турбокомпрессоров и др.

В отличие от электроэнергии теплота (особенно при теплоносителе - паре) не может быть экономично подана на очень большие расстояния, поэтому каждому предприятию или группе близко расположенных предприятий требуется свой источник теплоты нужных параметров. Такими источниками являются теплоэлектроцентрали (ТЭЦ), на которых производится комбинированная (совместная) выработка теплоты и электрической энергии.

ТЭЦ вырабатывает электрическую энергию и тепло, отпускаемое в виде пара и горячей воды. Использование в практических целях отработавшего тепла двигателей, вращающих электрические генераторы, является отличительной особенностью ТЭЦ и носит название теплофикация. Комбинированное производство энергии двух видов способствует более экономному использованию топлива по сравнению с раздельной выработкой электроэнергии на конденсационных электростанциях и тепловой энергии на местных котельных установках.

ТЭЦ обладают рядом преимуществ [1]:

1. Используемое топливо достаточно дешево.

2. Требуют меньших капиталовложений по сравнению с другими электростанциями.

3. Могут быть построены в любом месте независимо от наличия топлива.

4. Занимают меньшую площадь по сравнению с гидроэлектростанциями.

5. Стоимость выработки электроэнергии меньше, чем у дизельных электростанций.

Начиная с 90-х годов прошлого века, значительно снизилось потребление тепловой и 
электрической энергии от ТЭЦ, не смотря на всю их эффективность. Одной из причин этого явилось несовершенство принципов формирования себестоимости энергетической продукции. Каждая станция в праве выбрать любой способ распределения затрат комбинированного производства. Однако при всем многообразии подходов, все они имеют недостатки. Проведена краткая характеристика наиболее часто встречающихся методов.

\section{Физический метод.}

В основу этого метода положено распределение затрат пропорционально количеству топлива, израсходованного на каждый вид энергии на основе теплового баланса. При этом полагается, что на получение тепловой энергии из отборов турбин затрачивается такое же количество топлива, как и при отпуске теплоты непосредственно из котлов.

При физическом методе расчета для установления стоимостных показателей производства электроэнергии и тепла общий расход топлива в комбинированном производстве условно делится на две составляющие: одна пропорциональна отпуску тепла потребителям, другая - остальному количеству тепла, которое относят на производство электроэнергии. Другими словами, все тепло, которое поступало в паровую турбину с перегретым паром за вычетом тепла регулируемых отборов, отданного на нужды теплоснабжения, относилось на производство электроэнергии. При этом на выработку единицы электроэнергии в раздельном производстве (на конденсационной электростанции) расходуется примерно в 1,5 раза больше тепловой энергии, чем при комбинированном производстве, поэтому очевидно, что при таком разделении расхода тепла (топлива) в последнем случае вся экономия от уменьшения его общего расхода относится к процессу производства электроэнергии [1].

Физический метод распределения расхода топлива применялся до 1996 г. на тепловых электростанциях России. Использование этого метода при расчете тарифа на электроэнергию и тепло в рыночных условиях привело к абсурдной ситуации: ТЭЦ оказались неконкурентоспособными на рынке тепла, промышленные предприятия в массовом порядке начали отказываться от покупки тепла у ТЭЦ и сооружать собственные котельные.

\section{Метод электрических эквивалентов.}

При распределении затрат по этому методу рассчитывается доля каждого вида энергии в общем объеме производства. Для сопоставимости все виды мощности и энергии выражаются в единицах электроэнергии, т.е. в кВт или кВт.ч. Используются различные коэффициенты - коэффициенты распределения для условно-постоянных и условно-переменных затрат. Условно-постоянные затраты определяются составом оборудования энергопредприятия, его суммарной установленной мощностью. Этот метод применяется в упрощенном виде, когда все виды затрат распределяются пропорционально количеству энергии, без учета их зависимости от режимов работы оборудования [1].

\section{Метод эквивалентной КЭС.}

Этот метод, впервые предложенный Вагнером, основывается на анализе влияния совместной выработки тепловой и электроэнергии на расход топлива и денежные затраты на энергетику страны в целом. Поскольку место сооружения ТЭЦ и ее мощность зависят от теплового потребления, то главным продуктом, по мнению разработчика метода, надо считать тепловую энергию. Использование ТЭЦ дает возможность отказаться от строительства и эксплуатации такой КЭС (или ее части), которая была бы необходима для выработки соответствующего количества электроэнергии [2].

\section{Эксергетический метод.}

В качестве альтернативы «физического» метода ряд ученых предлагали внедрить так называемый эксергетический метод. Данный метод основывается на втором законе термодинамики, характеризующим качество различных видов энергии [1].

Как известно, «физический» метод основан только на первом законе термодинамики, который характеризует количественную сторону процессов преобразования энергии, суммируя тепло любых параметров и электроэнергию без учета их качества (энергетической ценности) и является частным случаем всеобщего закона сохранения и превращения энергии применительно к тепловым процессам.

Основное отличие данного подхода от «физического» заключается в том, что при рассмотрении балансов энергоустановок принимаются во внимание не только количественные эквиваленты потоков энергии, но и потери ценности этой энергии в процессе ее преобразования. 


\section{Нормативный метод.}

Данный метод поддерживают Попырин Л.С, Денисов В.И., Светлов К.С.. Ученые выделяют следующие требования, предъявляемые к методу распределения затрат:

- отражать народнохозяйственную эффективность ТЭЦ;

- иметь четкий экономический смысл и понятную методику вычисления.

Всем этим критериям, с точки зрения авторов, и удовлетворяет нормативный метод, согласно которому разделение затрат в комплексном производстве происходит пропорционально соответствующим видам затрат при раздельном производстве заданных объемов тепловой и электрической энергии [2].

\section{Метод Денисова В.И.}

Важным для изучения является и метод, предложенный в 1999 году Денисовым В.И. Он позволят распределить суммарный расход топлива ТЭЦ между тепловой и электрической энергией, одновременно разделяя расхода топлива на электроэнергию, вырабатываемую по теплофикационному и конденсационному циклам [2].

\section{Энергетический метод.}

В 1995 году специалистами фирмы ОРГРЭС был разработан и введен с 1 февраля 1996 года новый энергетический («усредненный») метод. Он изменил методику распределения израсходованного энергетическими котлами ТЭС топлива между отпускаемыми видами энергии: электроэнергией и теплом.

Распределение расхода топлива, израсходованного энергетическими котлами, согласно внедренному методу, производится пропорционально затратам тепла на выработку электроэнергии и отпуск тепла внешним потребителям при условии их раздельного производства на конкретной электростанции [1].

Основной причиной разработки этого метода стало то, что с одной стороны, всеми признана необходимость увеличения доли затрат, приходящейся на ТЭЦ на производство электроэнергии (и тем самым уменьшения затрат на тепло), а с другой стороны это должно происходить не так резко, как при применении эксергетического метода. Поэтому метод, предложенный фирмой ОРГРЭС, принят для использования в качестве переходного от физического метода к более совершенному. Но несмотря на это, в действительности оказалось, что при расчетах по данному методу доля отнесения затрат на электрическую энергию в некоторых случаях оказалась даже больше, чем в случае применения эксергетического метода. Одной из причин этого может являться высокая сложность вычислений.

\section{Метод отключения.}

Суть метода заключается в том, что из суммарных затрат комбинированного производства исключаются затраты на побочные продукты, принимаемые условно по возможной цене их реализации.

Этот метод основан на принципе предельной себестоимости. Согласно ему - производство побочных видов продукции экономически целесообразности лишь в тех случаях, когда себестоимость их производства не превышает возможную цену их реализации. Предельной себестоимостью в данном случае является возможная цена реализации продукции. В энергетике этот метод нашел отражение при построении треугольника Гинтера [2].

\section{Метод коэффициентов.}

Этот метод основывается на применении средних коэффициентов, которые рассчитываются с помощью различных стоимостных, натуральных, технических и технологических показателей, характеризующих особенности комплексного производства или специфику получаемой в нем продукции.

Распределение общих затрат согласно данному методу происходит по коэффициентам, которые чаще всего принимаются пропорционально себестоимости продуктов при раздельном производстве или действующим оптовым ценам. В электроэнергетике этот метод назывался коэффициентом удешевления и применялся при калькулировании себестоимости энергии на ТЭЦ до 1937 года [2].

\section{Экономический метод.}

Следующий методом был предложен Сaфоновым Л.П., Смолкиным Ю.В., Суворовым П.П. Авторы, критикуют основные подходы к распределению затрат - эксергетический и «физический», указывая на их термодинамическую основу. Они считают, что задача определения цен в комплексных производствах является «экономической задачей и поэтому может решаться только экономическими методами» [2].

В результате анализа представленных выше методов можно сделать вывод, что при всем многообразии подходов, нет единого универсального способа, с помощью которого можно 
Таблица 1. Итоговые значения себестоимости энергии.

\begin{tabular}{|c|c|c|c|}
\hline \multicolumn{2}{|r|}{ Метод распределения затрат } & Sээ, коп. $/ \mathrm{KBT} \times \mathrm{Y}$ & Sтэ, руб/Гдж \\
\hline 1) & Физический метод & 126,93 & 179,08 \\
\hline 2) & Эксергетический метод & 123,21 & 185,26 \\
\hline 3) & Метод электрических эквивалентов & 86,12 & 247,16 \\
\hline 4) & Энергетический метод & 133,9 & 168,28 \\
\hline
\end{tabular}

было бы избавиться от перекрестного субсидирования в отрасли и повысить эффективность работы ТЭЦ [3].

Рассмотрено влияние основных методов распределения затрат на примере ТЭЦ-3 ООО «Тверская генерация». Тверская ТЭЦ-3 расположена в северной части города Твери на территории Заволжского района, к северу от поселка «Соминка» [4]. На ТЭЦ установлены: Турбины: ПТ-60-130/13 и Т-100-120/130. Котлы: БК3-210140-7, КВТК-100-150, КВГМ -180-150. Рассчитанные значения себестоимости тепловой и электрической энергии сведены в итоговую таблицу (таблица 1).

Множество методов, которыми можно воспользоваться при расчётах, позволяет ТЭЦ-3 ООО «Тверская генерация» (и любому предприятию) выбрать наиболее подходящий для неё вариант. Проанализировав влияние распределения затрат рекомендован эксергетический ме- тод, при котором себестоимость электроэнергии составляет 123,21 коп/кВт*ч ${ }^{*}$, а на себестоимость тепловой энергии 185,26 руб/ГДж.

По результатам анализа можно сделать вывод, что значение себестоимости тепловой энергии методом электрических эквивалентов превышает генерирующую составляющую тарифа на тепловую энергию. Поэтому данный метод неприменим для ТЭЦ-3 ООО «Тверская генерация». По остальным методам ограничения отсутствуют. Однако, значение себестоимости электрической энергии, рассчитанное энергетическим методом превышает цену, сложившуюся в результате торгов на РСВ. Так как ТЭЦ может самостоятельно выбирать метод распределения затрат, то предлагается использовать эксергетический метод, потому что значение себестоимости электрической энергии ниже, а значит можно продать больший объем электроэнергии.

\section{Библиографический список}

1. Рогалев, Н.Д. Экономика энергетики: учеб. пособие для вузов / Н.Д. Рогалев., А.Г. Зубкова, И. В. Мастерова 2-е изд., испр. и дополн.-М.: Издательский дом МЭИ, 2008.- 300 с.

2. Сухарева, E.B. Методы распределения затрат при формировании себестоимости энергии на ТЭЦ / Е.В. Сухарева // Транспортное дело России. - 2015.- № 3.- С. 43-45.

3. Сухарева, E.B. Особенности расчета тарифа на тепловую энергию методом «альтернативной котельной» / Е. В. Сухарева, Г.Н. Курдюкова, Д.Г. Шувалова // Экономические науки. - 2016. - № 11. С. 15-18.

4. Официальный сайт ООО «Тверская генерация» https://tvgen.ru/unit/view/2. 